\title{
Path Dependence: Determinants and Impacts of Technology Adoption
}

\section{Simeon Simeonov}

\begin{abstract}
Today's world heavily relies on sustained technological advancements. Yet, consumers' preferences for one technology over another are not necessarily predicated on transparent or rational reasons. That is, in a sequence of events later decisions are not entirely independent on previous ones. Historical choice patterns paired with positive feedback may subsequently reinforce one's entrenched ways of thinking. This resultant contingency, referred to as path dependence, may tip the balance in favor of one particular piece of technology over more superior ones. A better comprehension of the phenomena in terms of technology adoption suggests a greater probability of attaining the most optimal outcome. Thereby, the current paper aims to address the subtle corresponding determinants and impacts of technology adoption. Relevant studies thereat were selected, critically assessed, and integrated into the follow-up literature review. A thorough view at the inferior QWERTY keyboard attributed its entrenchment on a market level to three interrelated factors: technical interrelatedness, system scale economies, and quasi-irreversibility of investment. Although more superior alternatives were
\end{abstract}

available, the QWERTY keyboard layout is nowadays a leading standard worldwide.

Keywords: path dependence, technology adoption, initial conditions, positive feedback, QWERTY keyboard

JEL: D11, D91, E11, O33

\section{Introduction}

ife is full of choices. Everyday situations exert constant pressure upon people to make various decisions. Therewith, the steady increase of the influence technology has on every aspect of daily life impacts consumers' choices yet to be formed. Consistent with the neoclassical economics, the mainstream economics today argues that individuals have rational preferences and tend towards utility maximization (see, for example, Arnsperger \& Varoufakis, 2005, pp. 2-6). Moreover, it argues that a unique and most efficient outcome/ equilibrium will eventually be reached regardless of outside influences. External circumstances and influences, however, are what impugn individuals' behavior and rational choices. In terms of competition in the technology market, consumers form purchasing preferences based on multifarious factors (e.g., attitudes of others, brand popularity, price attractiveness). If choices for a certain technology made in the past appear satisfactory in the process, individuals are likely to make similar ones in the future or influence others in their choice. Collectively,

${ }^{1}$ University of National and World Economy, Faculty of International Economics and Politics 


\section{Articles}

the historical choice patterns coupled with the positive feedback by others are presumed to shape one's future purchasing decisions. Is it possible then that individuals demonstrate bounded rationality? If this appears to be true, what might the determinants and influences of technology adoption be? An adequate approach to the afore-raised questions is expected to provide a more comprehensive view of what makes our choices what they are and the extent to which we are able to mount resistance.

This phenomenon, also referred to as path dependence, was initially approached with great sensitivity by David (1985) in the article "Clio and the Economics of QWERTY". The focus was shifted to accidental historical events that had led to the further entrenchment of QWERTY keyboard on a market level. Thereafter, Arthur (1989) offered four interrelated features of a path dependent process - unpredictability, inflexibility, nonergodicity and potential path-inefficiency. In a similar vein, Liebowitz and Margolis (1995) proposed three distinct forms of path dependence each of which had implications in terms of market error and lock-in. As they also stated, only the third-degree path dependence impeaches the neoclassical paradigm as it may lead to several inefficient outcomes. Additionally, Ebbinghaus (2005) delineated two types of path dependence deterministic ("trodden trail") and developmental ("road juncture"). Despite the structural and ideological variances, common to both approaches is the understanding that further decisions are not entirely independent from prior ones in a sequence of events.

Although the concept of path dependence is fairly-well studied, scant research efforts appear to have been directed towards disclosure of specific determinants and impacts of technology adoption. The present literature review hence sets out to address their existence and effect thereof upon individuals' purchasing decisions for a certain technology over others.

Critiques of the concept in terms of inefficiency claims will not be considered in this paper.

\section{Review Methodology}

The research studies selected for the current literature review focus on path dependence with a further revelation of underlying determinants and impacts of technology adoption. After being subjected to meticulous scrutiny and analysis, they were carefully integrated into the follow-up literature review. The databases employed to search for relevant research studies are Academia, Core, ResearchGate, ScienceDirect, Springer, Semantic Scholar, and ProQuest. The following online journals were further accessed: Academy of Management Review, the International Journal of Industrial Organization, International Journal of Social Sciences, Tourism Geographies, and SSRN Electronic Journal. The date range of the suggested research materials is 1985-2015.

\section{Theoretical framework}

\section{The concept of path dependence}

Determined by its innate complexity, the path-dependent phenomenon has called for multi-disciplinary research over the years. Stochastic processes, mathematical tools, and biology models therefore found relevant implication (Castaldi, Dosi \& Paraskevopoulou, 2011 , p. 4). Further utilization of the concept proved useful at the macro (e.g., institutional persistence, economic development, political processes), meso (e.g., exploration of inferior technology, governance structures), and micro levels (organizational inertia in changing environments) (Meyer, 2012, p. 5). The concept of path dependence also finds 


\section{Articles}

relevance in social sciences in an attempt to explicate stability in diversified organizational, technological, and institutional settings ( $p$. 5). Regardless of collective contributions in the field, its initiation mostly stems from the pioneering influence of William Arthur and Paul David (Beyer, 2010, p. 1). The latter defines path dependence as a succession of economic changes triggered by temporarily remote events rather than systematic forces, affecting the potential outcome (Araujo \& Harrison, 2000, p. 2). Likewise, Meyer (2012) conceptualizes path dependence as small events intensified over the course of time by positive feedback mechanisms, allegedly resulted in an inefficient lock-in state ( $p$. 5). This hypothesis coincides with that of Sydow, Schreyögg, and Koch (2009) who termed it as a "rigidified, potentially inefficient action pattern", prejudiced by unsolicited consequences of prior decisions and positive feedback processes (p. 696). In other words, history matters and decisions made in the past affect later ones by reinforcing entrenched ways of thinking and routines (Mahoney, 2000; Ebbinghaus, 2005; Beyer,
Path Dependence: Determinants and Impacts of

Technology Adoption

2010; Castaldi, Dosi \& Paraskevopoulou, 2011; Dobusch \& Kapeller, 2011; Meyer, 2012). Further, Mahoney (2000) argued that most historical sociologists transcend the prevalent notion of correlation between past choices and future processes (p. 510). Their scientific endeavors seek to clarify the relevance of process, sequence, and temporality to the path-dependent explanation. Mahoney (2000) thus suggests three features inherent to the path-dependent analysis (pp. 510-511). First, it is the presence of random processes guided by events that occur in the early stages of an overall historical sequence. For instance, Brian Arthur's discussion of the Pólya urn experiment serves to exemplify that earlier parts of a sequence outweigh the importance of later parts (see, for example, Ebbinghaus 2005:7). Although it is always a random process, one color will dominate in the long-term owing to the positive feedback on already drawn balls of a particular color. That is, the order of events proves to matter as it impacts the sequence of their subsequent appearance and hence the ultimate outcome.

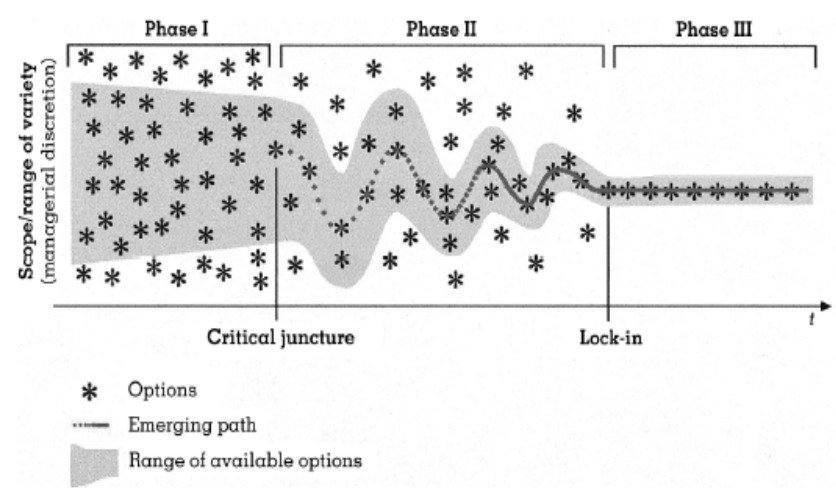

Figure 1: The "Berlin model": constitution of an organizational path. Adapted from Organizational path dependence: Opening the black box (p. 692), by Sydow, Schreyögg, \& Koch (2008)

Second come early historical events construed as contingent occurrences, exempted from interpretation by prior events or initial conditions. The ultimate outcome hereby cannot be accurately anticipated in the light of initial conditions. As Jack Goldstone inferred, path dependence is a property of a system the outcomes of which are linked 


\section{Articles}

rather randomly to initial conditions (as cited in Mahoney, 2000, p. 511). Referring back to the Pólya urn experiment, the final outcome remains unknown before the immediate selection of a color. An achievement of a steady equilibrium will be hence shaped by the random pick of certain colors.

The final integrated part of the path dependence process, suggested by Mahoney, is inertia. Essentially, it represents contingent historical events that came into being and were further marked as deterministic casual patterns:- Once processes are being activated and an outcome is selected, they tend to persist toward this particular outcome over the course of time. Moreover, inertia will shift on account of the type sequence analyzed - self-reinforcing or reactive. The former incorporates potent mechanisms projected to replicate institutional patterns over time. By contrast, the latter is represented by reaction and counteraction mechanisms designed to energize an event chain with inherent logic. As a result, one event naturally leads to a followup one. To foster a better comprehension of the concept, a model of path formation process follows for discussion. In conjunction with Sydow, Schreyögg, and Koch (2009), each of the three phases accentuates on innate diverse structural attributes and causal regimes (pp. 692-694).

As Figure 1 illustrates, the preformation phase (Phase 1) is typified by historically framed contingency. Outwardly inconsequential small events evoke a self-reinforcing process. According to Dobusch and Kapeller (2011), the significance of the former is twofold (pp. 9-10). First, the existence of small events and their influence upon the possible outcome is acknowledged by the dynamics. Second, their exclusion of an individual's ex-ante knowledge and resolving power determines the nonergodicity of the path dependence processes.
The preformation phase continues until a critical juncture marks its transition to the formation phase - Phase 2 (Dobusch \& Kapeller, 2011; Sydow, Schreyögg, \& Koch, 2009). Here initial decisions of the former stage are amplified over time by selfreinforcing processes, further constraining the scope of action. Interestingly, Saxenian refers to the self-reinforcement, positive feedback and increasing returns as an essential mechanism of path dependency, equivalent in the meaning attached (as cited in Dobusch \& Kapeller, 2011, p. 10). As she further alluded, the concept without it will solely highlight the importance of history. Likewise, Sydow, Schreyögg, and Koch (2005) consider the self-reinforcement as an increase of a single variable that leads to a further increase of this very same variable (p. 6). Along these lines, it is further noted that the selfreinforcing process acquires a spiral form of dynamics possibly resulting in a lock-in state or inflexibility. The afore-stated assertions tally with Arthur's who additionally delineates four sources of self-reinforcing mechanisms in economics (as cited in Araujo \& Harrison, 2000, p. 5; Beyer, 2010, p. 1; Schulte, 2015, pp. 9-10). The mechanisms present initial advantages relevant to the development of technological path dependence and generate barriers-cost that have to be overcome to quit the path (Schulte, 2015, p. 9). First, it is the high initial or fixed costs - carry less weight when larger quantities are present. Second, the learning effects - contribute to highquality products or retrench production costs. Third, the coordination effects - emanate from opportunities for collaboration when economic actors make analogous decisions. Lastly, it is the adaptive expectations - situations where a product's prospective usage is determined by its present distribution.

The final lock-in phase of the path formation (Phase 3) outlines a stable equilibrium 


\section{Articles}

wherein "alternative courses of action" are no longer conceivable. According to Ebbinghaus (2005), similar rigidity is promoted by individuals' corresponding investments in the dominant path (e.g., sunk costs and time) ( $p$. 10). Their reluctance to exchange a chosen alternative for others, even if proven to be more beneficial, is thereupon likely to take precedence. To exemplify, one's preferences for one particular internet browser and further displayed aversion to switch to any alternative available reflects the self-invested time of adjustment.

Curiously, Ebbinghaus (2005) differentiates between two types of path dependency deterministic (trodden trail) and developmental (road juncture) (pp. 8-10). The former deals with the unsolicited evolution of an institution and its further long-term entrenchment. It enlists four critical ingredients, briefly disputed hereinbefore. First, equal starting conditions with the same initial expectancy is assumed. Multiple equilibriums are likely to exist as the path selection is destined by a chance in the early stages of the process (see the Pólya's urn experiment). Second comes the self-reinforcing process. As already discussed, it is a social mechanism accountable for an alternative to outmatch others through network effects. For instance, the set-up and subsequent continuous use of the social communication platform Facebook presently have led to billions active users. Third, follows the solidified lock-in state that embodies a stable equilibrium. Lastly, the three crucial afore-mentioned components of path dependence signal for a potentially reinforced inefficiency. Inasmuch as several outcomes are assumed and early small events randomly determine the path to be chosen, inefficient outcomes are likely to emerge. The deterministic model per se is recognized to adequately explain solitary stable cases of path dependence, promoted by stochastic
Path Dependence: Determinants and Impacts of

Technology Adoption

events and self-reinforcing processes ( $p$. 11). It was consequently subjected to strong criticism relative to its incapability to consider individuals' respective counterstrategies to seek a change of course.

Conversely, the developmental model highlights the interrelated sequence of events that structure alternatives for imminent institutional changes. It spans three constructive components (Ebbinghaus, 2005, p. 15; Chen \& Bao, 2014, p. 816). First, it is the critical juncture - an institution appears thereof and collective actors establish new rules. The pathway selection is oftentimes a result of political conflicts and power relations. Second comes the process of institutionalization - it takes hold through self-reinforcing processes whereby positive feedback enables societal approval of a recently established institution. Lastly, follows the sequence of contingent decisions - once institutionalized, prior decisions structure the alternatives of subsequent ones. Ebbinghaus (2005) gave as an example the juridical principle of precedence which assumes constrained choice set in given circumstances. In line with the English customary law tradition, courts are normally restricted by previous judgments and an exception of the common tradition requires special reasons.

Ebbinghaus (2005) outlines three scenarios of institutional transformation since, as he stated, the developmental view of path dependence assumes more openness to change (p. 17). First, it is the path stabilization - slight adjustment to environmental changes while core principles remain intact. Second, the path departure - gradual adjustment via a partitive resumption of institutional arrangements and limited redirection of core principles. Lastly, the path switching - the self-reinforcement of an established institution is discontinued and a new one is promoted to emerge. 


\section{Articles}

\section{Technological path dependence}

Path dependence is a constructive approach for understanding the centrality of decision making on the development and impact of certain technologies (Melosi, 2008, p. 1). The cornerstone of the concept rests on competing technologies and the market dominance of inferior technologies is a clear indication for its existence (Meyer, 2012, p. 8). According to Melosi (2008), a number of externalities lobby the adoption of technologies (p. 1). This conforms to Castaldi, Dosi, and Paraskevopoulou (2011), who state that certain technological choices are reinforced by increasing returns and network externalities in the production or adoption of technologies (p. 2). They also note that technological innovation and diffusion oftentimes display dynamic increasing returns that unravel in the course of time. Arthur implies that modern and complex technologies often display increasing returns as the more they are adopted and improved, the more attractive they are to a wider group of adopters (as cited in Melosi, 2008 , p. 3). When technologies compete for a market thereat insignificant events might tip the balance and the technology that acquired an early lead might corner the market, causing other technologies to become locked-out (p. 3). However, Arthur concedes that not all adopted technologies necessarily enjoy increasing returns but it may prove useful to know to what extent the economy may be locked-into inferior technology paths (p. 3).

\section{Arthur's model of competing technologies}

Table 1: Pay-off function of competing technologies Adapted from Path dependence in two-sided markets (p. 11), by T. G. Meyer, 2012

\begin{tabular}{lcc}
\hline & \multicolumn{2}{c}{ Returns to choosing } \\
\cline { 2 - 3 } & Technology A & Technology $B$ \\
\hline R-type agent & $a_{R}+r n_{A}$ & $b_{R}+r n_{B}$ \\
S-type agent & $a s+s n_{A}$ & $b s+s n_{A}$ \\
\hline
\end{tabular}

The model assumes that an infinitely great number of agents adopt either technology A or B (as cited in Meyer, 2012, pp. 11-14). Agents ( $R$ and S-type) are equal in number and their choices present a constant individuals cannot switch to another technology afterwards. Table 1 displays their pay-off function when preferences are made towards either technology $\mathrm{A}$ or $\mathrm{B}$. The basic assumptions of the model are as follows. First, R-type agents developed a natural liking for technology $A\left(a_{R}>\beta_{R}\right)$. Conversely, S-type agents developed a natural liking for technology B ( $a S<\beta_{s}$ ). Second, agents' choice patterns are prejudiced by previous adopters of the respective technology, designated as $n_{A}$ and $n_{B}$. Third, the direction of influence is determined in terms of three distinctive returns regimes. Under constant returns to adoption $(r, s=0)$, the payoffs remain unchanged by the number of other adopters. In other words, both agent types always confine to the most preferred technology unaffected by others' choice patterns. Under diminishing returns to adoption ( $r, s<0)$, the appeal of technologies decreases as the adoption increases. Agents confine to their most preferred technology as long as it is not ahead of an alternative one by a certain number of adopters. Under increasing returns to adoption ( $r, s>0)$, both technologies generate higher payoffs in proportion to their adoption. Agents confine to their most preferred technology except for cases when an alternative one is, by chance, ahead by a certain number of adopters. When the latter situation is present R-type agents select technology $B$, regardless of their natural liking for $A$. The opposite for S-type agents is true as well. As a result, the adoption process acquires a random walk with absorbing barriers (see Figure 2).

Lastly, agents enter the market in a random fashion. The sequence of their choices being made is unknown ex-ante and is influenced by 


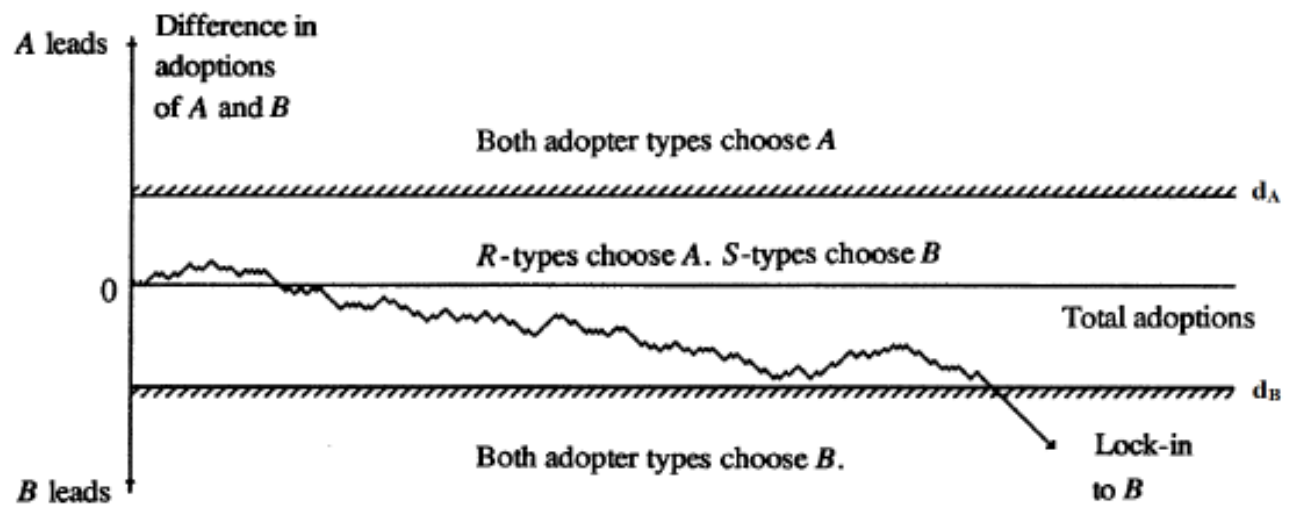

Figure 2: A random walk with absorbing barriers Adapted from Path dependence in two-sided markets ( $p .13)$, by T. G. Meyer, 2012

stochastically occurring small events outside the model.

As Figure 2 shows, the adoption of either A or $B$ technology is determined by the random choice sequence of both agents with equal chances (R-type for A, S-type for B). Being contingent on the step towards technology $A$ ('up') or B ('down') with an equal probability of 0.5 , the adoption process acquires a random walk.

According to Meyer (2012), if by some chance a number of S-type agents enter the market in a row (e.g., R-S-S-S-S) technology $B$ will be preferential in market share. The distinct advantage of technology B over technology A thereafter will lead to a growing number of adopters in favor of the former. By contrast, the same scenario holds true for technology $A$ if early random events tip the market in favor of agent R. The lock-in mechanism will be activated once the random walk strides over the upper frontier $d_{A}$ or sinks below the lower one $d_{B}$, accordingly.

\section{Properties of path-dependent processes}

Along these lines, Arthur delineates four attributes relevant to the path dependent process: unpredictability, inflexibility, nonergodicity, and possible path-inefficiency (as cited in Meyer, 2012, pp. 15-17). First, its unpredictability derives from the fact that the ultimate outcome is determined by occurring random small events early on in the process. Referring back to Arthur's model, the random choice sequence of the agents makes the outcome of the adoption process unknown exante. Second, its inflexibility basically means that alternative courses of action are no longer feasible after any particular path has been selected (lock-in state). With reference to Arthur's model, when the adoption process strides over either of the two absorbing barriers, the process is further pushed towards the outer frontier. As a result, one of the two technologies will quit the market. Third, nonergodicity means that several outcomes are possible and transient factors early on in the process dictate which path will be taken. A different sequence of randomly occurring small events hence will produce other results. Finally, the claim of potential path-inefficiency seems relevant as several outcomes with different efficiency rates exist and randomly occurring small events determine which path to be taken. 


\section{Articles}

\section{Cases of path dependence}

The QWERTY keyboard layout, among the most apt examples, putatively has had an advantage over alternatives (Schulte, 2015, p. 9). Another proverbial instance would be the videotape format war Betamax versus VHS (see, for example, Liebowitz \& Margolis, 1995, pp. 3-16). As Schulte (2015) adduced, both technologies (i.e., QWERTY \& VHS) further appeared suboptimal choices but their entrenchment on the market level drove the competition out of the race (p. 9). Looked from this angle at path-dependence, the caused lock-in state affects newly entered the market actors whose decisions are impacted by history choices of others (Schulte, 2015). The case presented below strives to promote an indepth comprehension of the path dependence phenomenon in terms of determinants and impacts of technology adoption, discussed at length hitherto.

\section{Dvorak versus QWERTY}

Avenues for further exploration of path dependence stem from David's seminal work on QWERTY's dominance over technically more superior alternatives (Meyer, 2012, pp. 8-9). Early models of the typewriter displayed such blemish resulted in jammed type bars when keys were used in rapid succession. Later on, the malfunction was partially adjusted by subsequent rearrangement of key ordering. The initial alphabetical key arrangement was thence superseded by the QWERTY layout originating from the topmost row of letters. Remarkably, the upper row also spans all keys required to type the word "typewriter" which was oftentimes used as a sales approach to attract customers. The launching of "touch typing" as a superior innovation compared to the "four-finger huntand-peck method" was integrated within the QWERTY keyboard (David, 1985, p. 334). Ultimately, the layout keyboard was acquired by E. Remington \& Sons, soon branded as Remington № 2 machines in 1878 (Meyer, 2012, p. 9). Along these lines, Meyer (2012) outlined the layout's change of relevance in technical necessity terms as the further implication of the cylindrical typewheel eliminated the issue of jamming type bars. Refined typewriter designs led to modified keyboard arrangements that appeared to be more pragmatic. Over the course of decades, a number of advanced keyboard layouts have been released on the market. Among the most significant ones, the Dvorak Simplified Keyboard relied on principles of human psychology and letter frequency in the English language. Thereby, it was widely conceived as superior over the QWERTY keyboard in terms of typing speed, error rates, training time, and comfort of usage. The continued technological progress in typewriter design enfeebled the practical relevance of the latter. Also, the inferiority of the QWERTY keyboard was predestined by the gradual appearance of personal computers that led ultimately to the total disappearance of typewriters.

Interestingly, the QWERTY keyboard not only reaped the benefit of further adoption but is nowadays a leading standard worldwide, regardless of respective market developments. Its desirability and subsequent entrenchment on a market level thereof evoke ambiguity and perplexity. This spin-off, also referred to as lock-in, was imputed by David to the dynamics of a complex system of interrelated agents: manufacturers and buyers of typewriters, professional typists, and training providers of touch-typing skills (Meyer, 2012, p. 9). Unlike Arthur who pinpoints increasing returns as the sole premise for path-dependent stabilization, David assigns the market dominance of the QWERTY standard to three features of the system (Beyer, 2010, p. 2; Meyer, 2012, p. 10). First, it is the technical interrelatedness - the technology's utility runs up if the arrangement 


\section{Articles}

of keys matches users' learning background. Companies thus found it more reasonable to select QWERTY typewriter models as many professional typists had already been accustomed to its application. Besides, progressive sales of the model urged more professional typewriters to invest time in mastering it as to become more marketable. Second, the system scale economies - rising economies of scale contribute to reduced production costs in any market share gained. As the number of QWERTY-trained typists increased, it was possible to set-up lower wages followed by reduced overall costs for maintaining the typewriting system. Training providers, on the flip side, generated lower costs as hired typewriters were fairly acquainted with the model. Lastly, the quasiirreversibility of investment - a reinforced lock-in state that ensues from the nature of learning and habituation. Once users became used to the QWERTY keyboard layout, any sequential change would have led to high switching costs of retraining for any alternative one.

By and large, David (1985) posits that the occurrence of historical accidents paired with positive feedback mechanisms to be accountable for pushing "the industry prematurely into standardization of the wrong system" (p. 336). Referring back to the example of the QWERTY keyboard, he attributes the initial lead in adoption to its association with the best-known Remington typewriter model. The slight advantage gained is further maximized over time through the foregoing effects of technical interrelatedness, economies of scale and the quasi-irreversibility of investment.

\section{Limitations and Future directions}

The current paper aimed to shed light on the concept of path dependence and further address the subtle corresponding
Path Dependence: Determinants and Impacts of Technology Adoption

determinants and impacts of technology adoption. Consistent with the attempted critical and comprehensive approach, the present paper clearly sets forth the nature, attributes, mechanisms, and applications of path dependence. Moreover, it also concisely spotlights the specific determinants and impact of technology adoption, i.e. technical interrelatedness, economies of scale and quasi-irreversibility of investment. Irrespective of its above-mentioned contributions to the scientific literature, the present study undisputedly illustrates several limitations. One limitation is attended with the inefficient claims and flaws of the concept, disregarded for the purpose of the study. Another limitation appertains to the limited practical examples that the analysis of the corresponding determinants and impacts are predicated on - Betamax versus VHS and QWERTY versus Dvorak Simplified Keyboard. Therefore, an appropriate avenue for further research would be to validate the afore-discussed determinants and impacts across related cases and in conformity with today's customer behavior trends. Another prospective avenue is to address possible strategies to invert the inflexibility of the path chosen and ultimately seek an alternative course of action. It is also reasonable to challenge the practical relevance of the concept if the positive feedback mechanism is assumed to be excluded from the model or instead we have a negative one.

\section{Conclusion}

The comfort of today's multifaceted life admittedly hinges on sustained technological advancements and innovations. Regardless of their general proclivity for utility maximization, individuals also somewhat appear to demonstrate bounded rationality. It implies that one's sound decision making is constrained by the information available, 


\section{Articles}

the cognitive limitations of the mind, and the response time required. Moreover, prior purchasing decisions may influence later ones through self-related attitudes and experiences. Satisfactory past preferences related to a certain technology are thereby likely to generate similar future purchases and even allow individuals to impact others in their choosing. Various externalities paired with historical choice patterns and others' positive feedback may or may not ultimately contribute to sub-optimal outcomes. A path dependence phenomenon is primarily a constructive approach for understanding the centrality of decision making on technology adoption. The concurrent operation of the factors technical interrelatedness, system scale economies, and quasi-irreversibility of investment cause fairly more advanced technologies to become locked-out from the market. A sufficient comprehension of the concept in reference to technology adoption will help individuals attain the most efficient outcome. Nonetheless, the concept still undergoes constructive developments as there are dimensions yet to be crystallized and studied.

\section{References}

Araujo, L. \& Harrison, D., 2000. Technological Trajectories and Path Dependence (1st ed., pp. 2-5). Retrieved from http://www.impgroup. org/uploads/papers/292.pdf.

Arnsperger, C. \& Varoufakis, Y., 2005. What is Neoclassical Economics? The Three Axioms Responsible for its Theoretical Oeuvre, Practical Irrelevance and, thus, Discursive Power (1st ed., pp. 2-6). Retrieved from http:// www.axiomaticeconomics.com/Varoufakis_ Arnsperger.pdf.

Beyer, J., 2010. The Same or Not the Same On the Variety of Mechanisms of Path Dependence. International Journal of Social Sciences, 5(1), 1-2. Retrieved from https:// www.wiso.uni-hamburg.de/fileadmin/sowi/ soziologie/institut/Beyer/Beyer_IJSS.pdf.

Castaldi, C., Dosi, G., \& Paraskevopoulou, E., 2011. Path Dependence in Technologies and Organizations: A Concise Guide (1st ed., pp. 2-4). Retrieved from http://www.lem.sssup.it/ WPLem/files/2011-12.pdf.

Chen, G. and Bao, J., 2014. Path Dependence in the Evolution of Resort Governance Models in China. Tourism Geographies, [online] 16(5), p.816. Available at: https://www.researchgate. net/publication/271928457_Path_ dependence_in_the_evolution_of_resort_ governance_models_in_China [Accessed 12 Feb. 2020].

David, P., 1985. Clio and the Economics of QWERTY. The American Economic Review, 75(2), 334-336. Retrieved from http:// econ.ucsb.edu/ tedb/Courses/Ec100C/ DavidQwerty.pdf.

Dobusch, L. \& Kapeller, J., 2011. Striking New Paths: Theory and Method in Path Dependence Research (1st ed., pp. 9-10). Retrieved from http://www.dobusch.net/pub/uni/DobuschKapeller(2012)Striking_New_Paths-Preprint. pdf.

Ebbinghaus, B., 2005. Can Path Dependence Explain Institutional Change? Two Approaches Applied to Welfare State Reform (1st ed., pp. 7-17). Cologne: Max Planck Institute for the Study of Societies. Retrieved from http://www. econstor.eu/obitstream/10419/19916/1/dp052.pdf.

Liebowitz, S. \& Margolis, S., 1995. Path Dependence, Lock-In, and History. SSRN Electronic Journal, 11 (1), 3-16. http://dx.doi. org/10.2139/ssrn.1706450.

Mahoney, J., 2000. Path Dependence in Historical Sociology. Theory and Society, 29(4), 510-511. Retrieved from https://www.ethz.ch/ content/dam/ethz/special-interest/gess/ computational-social-science-dam/ documents/education/Fall2009/simulation/ MahoneyPathDependence.pdf. 


\section{Articles}

Melosi, M. 2008. Path Dependence and Urban History: Is a Marriage Possible? (1st ed., pp. 1-3). Retrieved from http://www. geschundkunstgesch.tu-berlin.de/fileadmin/ fg95/Melosi_Text.pdf.

Meyer, T., 2012. Path Dependence in TwoSided Markets. A Simulation Study on Technological Path Dependence with an Application to Platform Competition in the Smartphone Industry (1st ed., pp. 5-17). Retrieved from http://www.diss.fu-berlin.de/diss/servlets/MCRFileNodeServlet/FUDISS_derivate_000000012507/Meyer_2012_Path_dependence_in_two_sided_markets.pdf;jses sionid=8BE339B6B609CFE772E952E56C4 2116B?hosts= Schulte, B. (2015). Theoretical Foundation - Path Dependence, Consumer Behavior, and Service Relationship Research. Staying The Consumption Course, 9-10. http://dx.doi.org/10.1007/978-3-65808788-3_2.
Path Dependence: Determinants and Impacts of Technology Adoption

Schulte, B., 2015. Theoretical Foundation Path Dependence, Consumer Behavior, and Service Relationship Research. Staying The Consumption Course, 9-10. http://dx.doi. org/10.1007/978-3-658-08788-3_2.

Sydow, J., Schreyögg, G., \& Koch, J., 2005. Organizational Paths: Path Dependency and Beyond (1st ed., p. 6). Retrieved from http://www.wiwiss.fu berlin.de/forschung/ pfadkolleg/downloads/organizational_paths. pdf.

Sydow, J., Schreyögg, G., \& Koch, J., 2009. Organizational Path Dependence: Opening The Black Box. Academy of Management Review, [online] 34(4), pp.692-696. Available at: https://www.researchgate.net/ publication/228807334_Organizational_ Path_Dependence_Opening_the_Black_Box [Accessed 12 Feb. 2020]. 